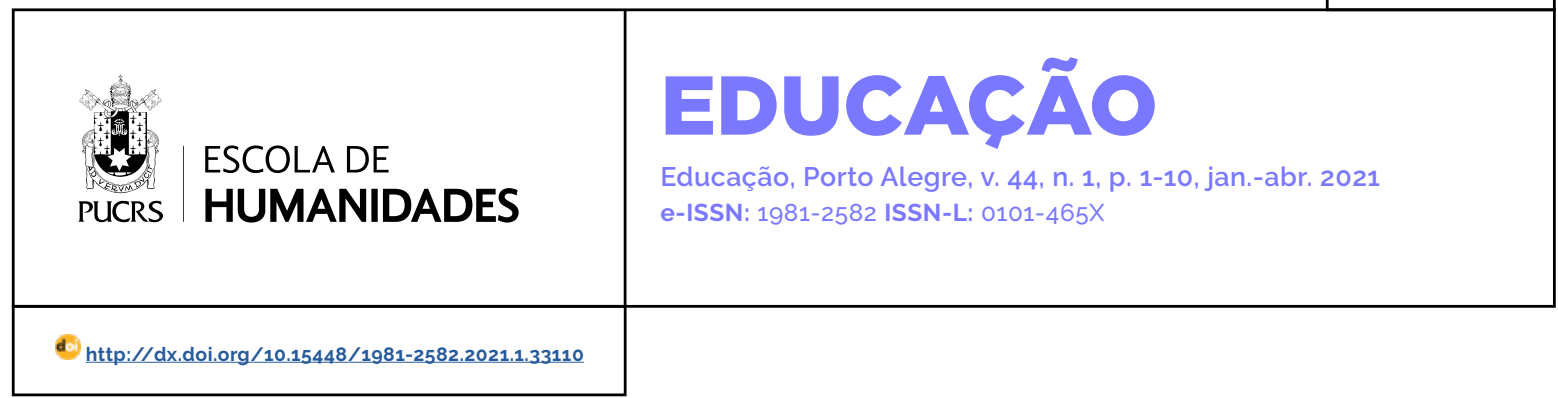

\title{
A construção do conhecimento na extensão universitária a partir de uma experiência freireana
}

\author{
The construction of knowledge in the university extension from a freireana experience \\ La construcción del conocimiento en la extensión universitaria a partir de una \\ experiencia freireana
}

\section{Adriana Giaqueto \\ Jacinto ${ }^{1}$ \\ orcid.org/0000-0003-0181-2839 \\ drigiaqueto@gmail.com \\ Eliana Bolorino \\ Canteiro Martins ${ }^{1}$ \\ orcid.org/0000-0002-7796-8437 \\ elianacanteiro@terra.com.br}

Recebido em: 22 jan. 2020

Aprovado em: 9 abr. 2021.

Publicado em: 21 jun. 2021
Resumo: Nos moldes da sociedade capitalista, sempre irá perdurar a existência de opressores e oprimidos e, portanto, podemos considerar que o legado de Paulo Freire continua atual para aqueles que se consideram educadores que buscam outra sociabilidade possível. Dentre os seus pensamentos destaca-se suas persistentes reflexões sobre o diálogo. Destacamos o Projeto de Extensão Universitária "NECRIA - Núcleo de Estudos e Extensão sobre Criança e Adolescente- e o ECA na escola", o qual realizou ao longo de sua trajetória uma ação educativa com crianças de uma escola estadual do ensino fundamental, uma atuação pautada na teoria de Paulo Freire. Trazer os fundamentos da relação dialógica em Paulo Freire para compreender os desafios trilhados pelo referido projeto de extensão universitária é o que se propõe nos limites desse artigo.

Palavras-chave: educação, ação dialógica, extensão universitária

Abstract: In the molds of capitalist society, the existence of oppressors and the oppressed will always endure, and therefore we can consider that the legacy of Paulo Freire remains current for those who consider themselves educators seeking another possible sociability. Among his thoughts it stands out his persistent reflections on dialogue. We highlight the University Extension Project "NECRIA - Nucleus of Studies and Extension on Children and Adolescents - and the ECA in school", which carried out along its trajectory an educational action with children of a public elementary school, a guided action in Paulo Freire's theory. Bringing the foundations of the dialogical relationship in Paulo Freire to understand the challenges experienced by the said university extension project is what is proposed within the limits of this article.

Keywords: education, dialogic action, academic extension

Resumen: Em los moldes de la sociedad capitalista, siempre perdurará la existencia de opresores y oprimidos y, por lo tanto, podemos considerar que el legado de Paulo Freire sigue siendo actual para aquellos que se consideran educadores que busca notra sociabilidad posible. Entre sus pensamientos destaca sus persistentes reflexiones sobre el diálogo. Destacamos el Proyecto de Extensión Universitaria "NECRIA - Núcleo de Estudios y Extensión sobre Niño y Adolescente - y el ECA em la escuela", el cual realizó a lo largo de su trayectoria una acción educativa com niños de una escuela pública de la enseñanza fundamental, una actuación pautada em la teoria de Paulo Freire. Traerlos fundamentos de la relación dialógica en Paulo Freire para compreender los desafíos vivenciados por el referido proyecto de extensión universitaria es lo que se propone dentro de los límites de ese artículo.

Palabras claves: educación, acción dialógica, extensión universitaria 
O Núcleo de Estudos e Extensão sobre Criança e Adolescente (Necria) surgiu em 2003 a partir do interesse de estudantes do curso de Serviço Social de uma universidade pública, inicialmente como grupo de estudos e em 2006 resolveram desenvolver trabalho com a comunidade, ampliando para a extensão também. O grupo avaliou na época que a falta de informações a respeito dos próprios direitos por parte das crianças era um fator que contribuía para as dificuldades de exercício da cidadania ao longo da vida. Dessa forma, a ideia inicial era desenvolver um trabalho de informação e reflexão sobre o Estatuto da Criança e do Adolescente com crianças de escolas públicas, preferencialmente as que estudavam em bairros periféricos e mais vulnerabilizados econômica e socialmente.

Assim foi criado o projeto "Necria e Eca na escola", sendo desenvolvido sistematicamente desde então. O projeto visava, então, à realização de um trabalho educativo em uma escola pública, com o objetivo de informar, orientar e estimular a reflexão crítica por parte das crianças matriculadas no ensino fundamental, sobre os direitos fundamentais garantidos pelo Estatuto da Criança e do Adolescente (ECA), estimulando a ampliação das possibilidades de sua efetivação.

O grupo de estudantes buscou apoio dos docentes, sendo que o projeto foi cadastrado em um órgão de fomento à extensão na universidade e acompanhado por um ou mais docentes durante sua trajetória.

Sempre foi consenso que a metodologia de abordagem e de produção de conhecimento deveria se dar de forma que todos os envolvidos, desde os estudantes extensionistas até as crianças atendidas na escola, pudessem ter uma participação ativa e fossem considerados como sujeitos do processo e não como objetos passivos, que apenas receberiam informações. Pelo contrário, o grupo entendia que esta deveria ser uma construção conjunta, em que todos poderiam aprender e ensinar ao mesmo tempo. A formação no curso de Serviço Social não contava com conteúdo referente à didática, à educação, ao ensino fundamental, mas o seu projeto político pedagógico contemplava os direitos humanos, as politicas sociais e o trabalho do/a assistente social fundamentado em um projeto ético-politico cuja perspectiva é outra sociabilidade, não gestada pela exploração nas relações de trabalho e de vida humana, contra a desigualdade social, enfim. O/A assistente social é um profissional que desenvolve trabalho eminentemente educativo, uma vez que nas relações com os usuários de seus serviços, busca uma troca e construção de conhecimentos que possam contribuir para o acesso ampliado aos direitos sociais, os quais são insistentemente negados às classes mais oprimidas pela exploração no trabalho.

Neste sentido, o caminho para esta aprendizagem mútua não poderia ser outro senão pela via do diálogo. Mas qual diálogo buscar? Dessa forma, o encontro com as ideias de Paulo Freire foi inevitável, especialmente a respeito do conceito referente ao diálogo (Freire, 1982), que é a essência da educação como prática de liberdade, sobre a dialogicidade, as relações homens-mundo.

\begin{abstract}
O diálogo é este encontro dos homens, mediatizados pelo mundo, para pronunciá-lo, não se esgotando, portanto, na relação eu-tu. Esta é a razão por que é possivel o diálogo entre os que querem a pronúncia do mundo e os que não a querem; entre os que negam aos demais o direito de dizer a palavra e os que se acham negados deste direito. (Freire, 1982, p. 93)
\end{abstract}

Esse diálogo significa estar aberto à escuta do outro e olhar o conteúdo a partir do ponto de vista do outro, com abertura e disposição para mudar o próprio ponto de vista.

Paulo Freire não criou simplesmente um método de alfabetização, mas criou uma compreensão de educação, uma epistemologia, dentro da qual existe a possibilidade de que as pessoas se alfabetizem lendo a palavra, ao mesmo tempo que leem o mundo, através da conscientização. Trata-se de uma leitura de mundo através da educação não bancária, mas que passa pelos temas fundamentais da obra de Paulo Freire: inacabamento, conscientização e práxis transformadora.

É a partir da concepção de educação de Paulo Freire que compreendemos a extensão univer- 
sitária, quando os extensionistas e os individuos envolvidos neste processo tornam-se "sujeitos" de transformação, através da "comunicação". Assim, "o conhecimento não se estende do que se julga sabedor até aqueles que se julga não saberem; o conhecimento se constitui nas relações homem-mundo, relações de transformação, e se aperfeiçoa na problematização crítica destas relações" (Freire, 1982, p. 36). Esse caráter educativo da atividade extensionista é parte integrante da pesquisa e do ensino. (Botomé, 1996).

Este debate de extrema relevância deve ser retomado principalmente em tempos de desmonte da universidade pública. Repensar a extensão não como mera transmissão de conhecimentos, acrítica, mas capaz de mobilizar reflexões, encontros de saberes no processo de construção de novos saberes, por isso a proposta de Paulo Freire em substituir o termo extensão por comunicação. ${ }^{2} E$ nessa premissa que sedimenta o desenvolvimento do projeto de extensão que será apresentado neste texto.

O Serviço Social encontrou no pensamento de Paulo Freire um terreno fértil para seu trabalho, principalmente após o movimento conhecido pela categoria profissional como "Reconceituação", ocorrido na década de 1970, em que se questionou o direcionamento ético e político do trabalho e consequentemente, todas as suas bases teóricas, metodológicas e éticas. As ideias freireanas foram uma das vertentes encontradas para fundamentar o direcionamento do trabalho nesta perspectiva.

Tendo surgido através de estudantes de Serviço Social, o projeto "Necria e o ECA na escola" buscou fundamentar-se no conhecimento de Paulo Freire, sendo que o estudo de várias obras foi um elemento essencial na trajetória de realização do referido projeto, contribuindo significativamente na formação profissional dos extensionistas.

Nos limites deste artigo, pretendemos realizar um relato desta experiência, destacando, além dos desafios encontrados, o que pudemos apreender a partir deste encontro com o pensamento freireano.

\section{O encontro com Paulo Freire: um processo inacabado}

A primeira demanda do grupo de estudantes extensionistas foi aproximar-se teoricamente das ideias de Paulo Freire e nesse sentido, foram conhecendo e apreendendo alguns conteúdos que direcionaram todo o trabalho de extensão.

Paulo Freire é um dos expoentes da educação popular, voltada para "os esfarrapados do mundo e aos que neles se descobrem e, assim descobrindo-se, com eles sofrem, mas, sobretudo com eles lutam" (Freire, 1982, p. 17). Toda sua obra contém um chamado ao Homem para ser mais humano, o que não é possivel em uma sociedade opressora. "A opressão só existe quando se constitui em um ato proibitivo de ser mais dos homens" (p. 47). Dessa forma, todos nós somos oprimidos em uma sociedade em que apenas alguns podem ser mais.

E por que Paulo Freire privilegiou a via da educação para falar da necessidade de transformação desta sociedade? Através de suas próprias palavras, podemos compreender que:
Não é possivel refazer este país, democratizá- -lo, humanizá-lo, torná-lo sério, com adoles- centes brincando de matar gente, ofendendo a vida, destruindo o sonho, inviabilizando o amor. (...) Se a educação sozinha não transforma a sociedade, sem ela tampouco a sociedade muda. (Freire, 2000, p. 65)

Pudemos através da realização deste trabalho compreender que realizar a educação popular tendo como base a teoria freireana significa realizar um trabalho de conscientização política, ou seja, de leitura crítica do mundo, que caminha junto com o processo de construção e reconstrução do conhecimento e que implica em ação, em intervenção no mundo.

A tomada de consciência não é um processo de caráter individual, mas sim social. Ela se dá na trama de relações que se estabelece com os outros homens e com o mundo, tornando-se processo de conscientização, por colocar cada homem de forma crítica diante da totalidade.

\footnotetext{
2 Pesquisar: Freire, P. (1977). Extensão ou comunicação? Paz e Terra. Importante também acompanhar os debates do Fórum de Pró-Reitores de Extensão das Universidades Pública brasileira (FORPROEX) e analisar a Política Nacional de Extensão Universitária.
} 
Sendo homem-mundo uma relação intimamente interligada, a consciência que o homem tem do mundo corresponde àquilo que se torna presente a ele de modo objetivado. Dessa forma, o mundo tornado objeto de seu conhecimento é reconhecido por ele impregnado de significados que the atribuiu, e essa experiência Paulo Freire define como "pronúncia do mundo".

A aptidão humana de compreender o mundo amplia-se cada vez mais a partir do desenvolvimento da capacidade de pronunciá-lo e o mundo só é mundo se dito por alguém. As trocas entre os homens efetivam-se pelo diálogo. Desse modo, quanto mais os homens envolvem-se em experiências de trocas de ideias, de opiniões, de conhecimentos, mais ampliam sua capacidade de dar sentido a sua compreensão de mundo.

Freire rejeita a concepção de educação como processo de adaptação do indivíduo à sociedade. Ao contrário, concebe o homem enquanto sujeito da própria educação, concluindo que "ninguém educa ninguém, como tampouco ninguém se educa a si mesmo: os homens se educam em comunhão, mediatizados pelo mundo" (p. 79).

Em sua proposta pedagógica, educar é essencialmente um ato político e é preciso fazer da conscientização o primeiro objetivo da educação, provocando uma atitude crítica, de reflexão, que comprometa a ação, sem submeter, domesticar, adaptar o ser humano, sem ajustálo à sociedade, mas promovendoo em sua própria linha de raciocínio. A educação popular proposta por Freire estimula a práxis social a partir de uma leitura crítica da realidade concreta. Ressaltamos a concepção de educação popular nas palavras de Paulo Freire:

Educação popular é a que, substantivamente democrática, jamais separa do ensino dos conteúdos o desvelamento da realidade. É a que estimula a presença organizada das classes sociais populares na luta em favor da transformação democrática da sociedade, no sentido da superação das injustiças sociais (...) critica também a natureza autoritária e exploradora do capitalismo. (Freire, 2007, p. 103-105)

Falando da importância do ato de ler no Congresso Brasileiro de Leitura (Campinas, novembro de 1981), ele afirma que:

\begin{abstract}
A leitura do mundo precede a leitura da palavra, daí que a posterior leitura desta não possa prescindir da continuidade da leitura daquele. Linguagem e realidade se prendem dinamicamente. A compreensão do texto a ser alcançada por sua leitura critica implica a percepção das relações entre o texto e o contexto. (Freire, 1989, p. 11)
\end{abstract}

Nesse processo de leitura e de releitura do mundo, de leitura e de releitura da palavra, uma leitura mais crítica do mundo e da palavra, forma o sujeito, que constrói uma visão de mundo e que pode, a partir desta visão, não apenas vê-lo, entendê-lo melhor, mas pode, assim fazendo, entender melhor como ele pode mudar pela ação. A existência humana não pode ser muda; os homens se fazem na palavra, no trabalho, na ação-reflexão. Dizer a palavra, por sua vez, não deveria ser privilégio de alguns homens, mas direito de todos (Freire, 1982, 1989, 2000).

O diálogo, no pensamento de Paulo Freire, constitui elemento fundamental no processo de educação popular, uma vez que é o encontro dos homens, mediatizados pelo mundo. Não é o momento onde só um expõe suas ideias, mas o momento em que dois ou mais trocam, aprofundam e lançam ideias. Para haver um efetivo diálogo entre as partes que dialogam é preciso mais do que troca de ideias; é necessário humildade, a fim de que não se veja no outro apenas um ignorante.

Os homens que não têm humildade ou a per-
dem, não podem aproximar-se do povo. Não
podem ser seus companheiros de pronúncia
do mundo. Se alguém não é capaz de sentir-se
e saber-se tão homem quanto os outros, é que
lhe falta ainda muito que caminhar, para chegar
ao lugar de encontro com eles. Neste lugar de
encontro, não há ignorantes absolutos, nem
sábios absolutos: há homens que, em comu-
nhão, buscam saber mais. (Freire, 1982, p. 95)

Para que o diálogo seja verdadeiro, faz-se necessário o pensar crítico; caso contrário, o que parece diálogo ou troca de ideias pode, na verdade, ser uma manipulação de ideias. Assim sendo, na perspectiva freireana uma educação dialógica não permite que o educador imponha sua visão de mundo ao educando, mas que dialogue com ele sobre a sua e a dele, que problematize a realidade concreta do educando, a 
fim de que este perceba se sua visão de mundo reflete a sua real situação de mundo. Dai a importância de a educação popular ser dialógica, ou seja, ter o diálogo como um de seus principais componentes. Até mesmo porque o processo de conscientização que propõe não é imposição, não pode ser manipulação.

Daí que, para esta concepção como prática da liberdade, a sua dialogicidade comece, não quando o educador-educando se encontra com os educandos-educadores em uma situação pedagógica, mas antes, quando aquele se pergunta em torno do que vai dialogar com estes. Esta inquietação em torno do conteúdo do diálogo é a inquietação em torno do conteúdo programático da educação. (Freire, 1982, p. 98)

Nesse sentido, não cabe ao educador que se pretende dialógico e problematizador impor conteúdos, mas sim devolver de forma sistematizada conteúdos que ele apreendeu dos saberes dos próprios educandos. Trata-se de um saber construído em diálogo permanente.

E que é o diálogo? É uma relação horizontal de A com B. Nasce de uma matriz critica e gera criticidade (Jaspers). Nutre-se do amor, da humildade, da esperança, da fé, da confiança. Por isso, só o diálogo comunica. E quando os dois polos do diálogo se ligam assim, com amor, com esperança, com fé um no outro, se fazem críticos na busca de algo. Instala-se então, uma relação de simpatia entre ambos. Só aí há comunicação. (Freire, 1994, p. 115)

O grupo extensionista foi compreendendo, no desenvolvimento do projeto que o conhecimento produzido juntamente com o grupo das crianças da escola nascia desse diálogo e era sempre inacabado, porque em construção permanente. Nesta linha de raciocínio, se o conhecimento não dialoga com a realidade do educando, contribui com o sentimento de que não é possivel mudar o mundo em que vivemos. É por isto que antes de definir quais os conteúdos são prioritários para determinados grupos ou qual a forma de abordagem é fundamental dialogar com esse grupo de educandos, conhecer as histórias de vida, os saberes, as diferentes realidades em que estão inseridos.

\section{O caminho percorrido pelo grupo de} extensão: o que foi possivel apreender

Inicialmente destacamos que os caminhos percorridos pelo grupo de extensão tiveram como pressuposto que a produção do conhecimento deveria ser efetivada por intermédio produzido de uma dialogicidade envolvendo os extensionistas, os coordenadores do projeto de extensão, os docentes e os estudantes (crianças da escola), ou seja, através da "comunicação" onde todos os integrantes desse processo se tornam sujeitos de transformação.

O grupo de estudantes extensionistas desenvolviam encontros, duas vezes por semana, com duração de duas horas cada um, com crianças de uma sala de aula da escola estadual. Nesses encontros, buscavam inicialmente conhecer essas crianças e seu universo, (familiar, os amigos, a cultura, o saber). Através de atividades lúdicas, levavam alguns conhecimentos sobre o ECA e principalmente, buscavam conhecer quais direitos estavam sendo desrespeitados para essas crianças e suas familias e a consciência que as mesmas tinham sobre seus direitos.

O grupo de estudantes extensionistas reunia-se toda semana com as docentes coordenadoras do projeto, para estudo, planejamento e avaliação das atividades desenvolvidas com as crianças. Esses momentos eram pedagógicos, não somente pelos estudos desenvolvidos pelo grupo, mas porque era um primeiro exercício de decodificação do real, para que os estudantes extensionistas, passando por esse processo, pudessem exercitar com as crianças o mesmo caminho de construção e desconstrução do conhecimento que eles mesmos estavam vivenciando.

As dificuldades que foram surgindo desde o início eram consideradas também enquanto conteúdo pedagógico e discutido no coletivo pelo grupo extensionista. Como exemplo, podemos citar a ideia equivocada, por parte dos gestores e professores da escola, de que o Estatuto da Criança e do Adolescente apenas reforça os direitos das crianças e dos adolescentes, sem, contudo, trazer os deveres. 
Outros desafios foram se apresentando no decorrer do percurso, entre eles, podemos citar o fato de que uma das salas de alunos disponibilizadas em um dos anos de execução do projeto era formada por crianças de uma instituição de acolhimento, as quais eram consideradas como "crianças problemas", esperando-se do projeto, que conseguisse promover mudanças positivas no comportamento das mesmas.

Neste mesmo ano, a escola em que o projeto era desenvolvido passava por uma mudança importante, que era a transformação para periodo integral e nesta fase de transição, a mesma se encontrava em condições precárias de trabalho, carecendo de atividades que preenchessem o tempo da criança na escola. Neste contexto, o projeto era oportuno, pois preenchia uma pequena lacuna na grade curricular. Ocorre que as crianças estavam submetidas a um ambiente de confinamento na maior parte do tempo, pois em um periodo assistiam às aulas e tinham reforço escolar no outro. Trabalhar com esta realidade foi extremamente desafiador, pois adentramos no universo da política de educação, que assim como as demais políticas públicas é resultante das determinações econômicas, sociais, políticas e culturais, espaço disputado, tensionado, considerando que incide na reprodução da ideologia dominante e, por outro lado, também reproduz as contradições que dinamizam os limites e possibilidades dos projetos societários em disputa na relação entre capital e trabalho.

A política de educação, em todas as suas modalidades e niveis de ensino, em tempos de capital fetiche, traduz o papel do Estado educador comprometido com os interesses do grande capital, condição imbricada nas propostas educacionais atualmente centradas na ampliação do acesso dos filhos da classe trabalhadora à educação escolarizada, com intuito de minimizar os altos indices de analfabetismo que marcam a trajetória da política de educação brasileira, respondendo aos preceitos ditados pelos organismos multilaterais internacionais.
Assim, a expansão da educação não potencializou a sua qualidade, contraditoriamente é destituída de infraestrutura necessária, atendendo principalmente os interesses do mercado, portanto, em evidente lógica de ampliação para menos, conforme analisa Algebaile (2009). Nesse sentido, não há valorização do conhecimento científico e propedêutico, muito menos a preocupação de uma formação crítica, libertadora, capaz de contribuir para uma cidadania ativa, consciente.

Nesse cenário, todos os sujeitos - professores, estudantes, familias - são vitimas desse sistema e, muitas vezes, são cooptados pelos valores do ideário neoliberal - individualismo, competitividade, fragmentação que incidem numa visão que se torna apenas capaz de visualizar a pseudoconcreticidade (Kosik, 1986), abstraindo as condições históricas, econômicas, sociais dos fenômenos sociais, principalmente os mais próximos da realidade da escola: problemas de frequência e evasão escolar; desinteresse dos alunos pela escola; a falta de participação da familia na escola; o trabalho infantil entre outros.

Diante desse retrato o desafio era o próprio fato de efetivar uma proposta desenhada na perspectiva de uma educação dialógica, libertadora, em atividades vivenciais, que remetem às experiências dos sujeitos, conforme apresentada por Freire - "educação que, superando a contradição educando-educadores, instaura-se como situação gnosiológica, em que os sujeitos incidem seu ato cognoscente sobre o objeto cognoscivel, que os mediatiza" (Freire, 1982, p. 78).

Os sujeitos (professores, alunos e famílias) presentes no cenário onde ocorreu o referido projeto (escola) e até mesmo os extensionistas, geralmente advindos de uma educação "bancária"3, precisavam desconstruir e reconstruir valores, posicionamentos que possibilitassem uma "olhar crítico" para a realidade social, tendo como premissa a racionalidade crítico-dialética e não formal-abstrata, meramente instrumental.

Esse foi um importante desafio, estabelecer uma relação dialógica também com os estudantes

\footnotetext{
3 Paulo Freire realiza uma crítica à educação em que o educador é o sujeito que conduz os educandos à memorização mecânica do um conteúdo narrado, de forma que se torna um ato de depositar, em que os educandos são os depositários e o educador o depositante (Freire, 1982, p. 63)
} 
universitários, integrantes do projeto de extensão, para que tivessem a oportunidade de conhecer outros horizontes, ou seja, uma proposta educativa libertadora, que possibilitasse um repensar dos seus valores e preconceitos, potencializando a relação que estabelecem com os sujeitos presentes no ambiente escolar e contribuindo, assim, com seu processo de formação profissional.

As reflexões, os planejamentos e avaliações das oficinas com estudantes constituiam um processo de aprendizagem para todos os envolvidos (inclusive os próprios docentes/coordenadores), interagindo saberes e experiências de vida, estabelecendo uma relação dialógica que promovia um repensar a realidade social, buscando a realidade concreta, pensada, em permanente movimento e não uma realidade abstrata, estática, a-histórica, vista com as lentes da imediaticidade. Assim, é possivel identificar as mediações na tríade da universalidade, singularidade e particularidade, conforme afirmam Paulo Netto e Falcão (1987):

na reconstrução do movimento da totalidade concreta, é a categoria mediação que assegura a alternativa da sintese das muitas determinações, ou seja, a elevação do abstrato ao concreto - mais exatamente, assegurando a apreensão da processualidade que os fatos empíricos (abstratos) não sinalizam diretamente. (p. 80)

É importante valorizar o conhecimento do educando, mas partindo daí, a curiosidade do educando para o conhecimento tem que ser aguçada. Nas condições de verdadeira aprendizagem, os educandos vão se transformando em reais sujeitos da construção e da reconstrução do saber, ao lado do educador, igualmente sujeito do processo. Se o diálogo é o encontro entre o refletir e o agir, não se reduz ao ato de depositar ideias nem simples troca de ideias a serem consumidas pelos permutantes (Freire, 1982). Na análise de uma situação existencial concreta "codificada" (representação da situação existencial com alguns de seus elementos constitutivos, em interação), se verifica o movimento de pensar, ou seja, a decodificação (análise crítica da situação codificada)

Fez parte do desafio do projeto em questão, portanto, de forma particular para os seus coorde- nadores, mobilizar nos estudantes extensionistas a efetivação da práxis (relação teoria-prática) no decorrer de todas as etapas da materialização da ação proposta no espaço educacional, portanto é imprescindivel referendar a prática como:

atividade objetivo-criadora do ser social - e o
trabalho é a sua forma ontológica-primária. É
a práxis que expressa a especificidade do ser
social. Seu desenvolvimento e complexidade
crescente é o indicador do desenvolvimento
e da complexidade crescente do ser social.
(Paulo Netto, 1994, p. 33 )

Neste movimento da práxis, o grupo fez diversas tentativas no sentido de ampliar sua contribuição com as expectativas da escola, realizando visitas domiciliares para conhecer a realidade das crianças, encontros diversos com pais e com os professores. Todas as atividades eram desenvolvidas com poucos recursos, contando prioritariamente com a criatividade e recursos dos próprios estudantes extensionistas.

Com as crianças, desenvolviam as oficinas com uma das salas do quarto ano do ensino fundamental (faixa etária entre 9 a 10 anos de idade), sendo a mesma escolhida pela direção da escola. Os estudantes extensionistas organizavam-se em grupos (sendo quatro integrantes por oficina) e iam ao encontro das crianças, inicialmente com propostas lúdicas, para conhecer o universo das mesmas, o conhecimento que elas tinham sobre os seus direitos fundamentais e a vivência destes direitos. A partir deste contato, o grupo de estudantes planejava cada oficina coma as professoras coordenadoras e após o desenvolvimento das atividades, avaliava a oficina e planejava a próxima, estudando os temas suscitados pelas crianças. Para este estudo, o grupo organizava-se também de forma coletiva e cada reunião era coordenada por uma dupla de estudantes.

Todos os participantes buscavam material de apoio, como textos, filmes, atividades lúdicas, materiais, que eram compartilhados pelo grupo. Desta forma, todo o processo de construção das oficinas era educativo, em que cada participante podia ir descobrindo a necessidade da rigorosidade na busca, isto é, exigia uma dedicação individual e coletiva, em que a contribuição de cada envolvido 
era considerada como fundamental. Os temas a serem trabalhados com as crianças na escola eram suscitados a partir dos encontros lúdicos em que se tinha como ponto de partida, os conhecimentos a respeito do Estatuto da Criança e do Adolescente. As atividades com as crianças eram pensadas enquanto uma proposta inacabada, uma vez que ao considerarem os ensinamentos de Freire, tinham como premissa que o momento educativo devia ser construido coletivamente, com educadores e educandos, processo que se aprende e se ensina ao mesmo tempo.

A experiência do projeto de extensão contribuiu para que as crianças do ensino fundamental pudessem expressar suas ideias, dúvidas, experiências cotidianas e pudessem ampliar os conhecimentos em um processo de interação de diferentes saberes, de diálogo. A partir da informação a respeito dos direitos previstos no ECA, as crianças refletiam e verbalizavam como elas e suas familias não estavam tendo garantidos estes direitos e contavam que levavam estas reflexões para casa, o que muitas vezes, suscitava novos diálogos.

A compreensão era a de que na promoção do diálogo, ouvindo o outro pelo exercício da alteridade é possivel uma ação libertadora da opressão, contribuindo para que os sujeitos possam recriar a sua própria história, alavancando e fortalecendo o processo de transformação dessa realidade social.

A "escola" como afirma Snyders (2005) é um espaço de contradição, portanto, apesar de estar fortemente voltada a perpetuar a ideologia dominante (no contexto contemporâneo de forma ainda mais evidente) também abriga o germe da contra-hegemonia (Gramsci, 1988), sendo, portanto, espaço de luta de projetos societários que se contrapõem em uma disputa permanente. É neste universo tensionado que a atuação com alunos e professores, conforme propõe o projeto de extensão são permeados por limites e possibilidades, que consideramos "desafios".

É necessário, então, desfazer os "mitos" para estabelecer um diálogo aberto entre aluno e professor. Para tanto, novamente recorremos a Paulo Freire que argumenta: "a metodologia que defendemos exige que no fluxo da investigação, se façam ambos sujeitos da mesma, tanto os investigadores como os homens do povo, que aparentemente seriam seus sujeitos" (Freire, 1982, p. 114).

Enfrentar os desafios inicia-se por compreender que o ato de educar é visto por Paulo Freire não como um processo de adequação do sujeito à sociedade, mas como um ato político que extrapola os muros escolares e a materialização tem como ponto de partida a interpretação do saber do povo para identificar formas de lidar com os diferentes saberes que permeiam a relação educador-educando.

É justamente nesse sentido que os integrantes do Projeto "NECRIA e o ECA na escola" empenharam esforços para "ouvir" os alunos e também os professores, visando compreender os saberes construíram no processo sócio-histórico que vivenciavam; somente assim seria possivel estabelecer de fato uma ação dialógica autêntica.

\section{Considerações finais}

A construção do projeto de extensão "NECRIA e o ECA na escola" foi, desde o início, inspirada no pensamento de Paulo Freire e, frente aos desafios apontados, continuamos a buscar em suas ideias, maneiras de decifrá-los e estratégias para enfrentá-los.

Desta forma, é o diálogo que apostamos como via de superação para os principais desafios encontrados. Lembramos que o diálogo verdadeiro pressupõe sujeitos da comunicação, em que ambos os comunicantes têm algo a dizer e, portanto, devem ser ouvidos. Aliás, escutar é o primeiro passo no processo que se quer construir de comunicação, pois é escutando que se aprende a falar com o outro e não a ele. Para saber escutar é preciso primeiramente controlara necessidade de dizer sua palavra, para que tendo o que dizer não seja o único a dizer. Dialogar é saber conviver com diferenças.

A tradição insiste em limitar a ação pedagógica à sala de aula. O referido projeto de extensão, coerente com o pensamento de Paulo Freire, pretendeu abrir os muros da escola, para ampliar o diálogo entre educando-educador, escola- 
-familia tendo como referência as experiências vivenciadas pelos indivíduos na vida social.

As considerações de Paulo Freire em torno da dialogicidade humana configuram-se como um significativo caminho de compreensão do ato educativo em busca de transformar o mundo humano, humanizando-o e aprendendo a humanizar sempre mais o próprio homem.

Como seu ponto de partida é a libertação dos oprimidos, pensar a educação como instrumento de mudança requer situar esta educação e esta mudança, tendo como pressuposto a realidade social na perspectiva da totalidade.

Na sociedade em que vivemos há limites para o diálogo, porque se trata de uma sociedade de classes, o que não quer dizer que o diálogo verdadeiro não pode ocorrer nas salas de aula, nos grupos com os quais trabalhamos. A experiência do projeto de extensão NECRIA, contribuiu para que os alunos do ensino fundamental pudessem expressar suas ideias, dúvidas, experiências cotidianas e pudessem ampliar os conhecimentos em um processo interação de saberes, de um diálogo horizontal entre eles e com os extensionistas.

Por isso que o diálogo não pode excluir o conflito. O diálogo de que nos fala Paulo Freire não é o diálogo romântico entre opressores e oprimidos, mas o diálogo para a superação da condição de oprimidos.

Não podemos esperar que uma escola seja comunitária em uma sociedade de classes; não podemos esquecer que a escola também faz parte da sociedade. Em uma sociedade de classes, toda educação é classista e na ordem classista, educar deve significar conscientizar e lutar contra esta ordem. Justamente nesse sentido que Paulo Freire propõe a educação problematizadora que mobilize a ação-reflexão e por essa práxis será possivel compreender a gênese, constituição e dinâmica da sociabilidade capitalista constituindo um processo de humanização que repercutirá na ação dos homens sobre o mundo na perspectiva de mudança.

A atuação dos estudantes extensionistas despertou o interesse em aprofundar os conhecimentos sobre os ensinamentos de Paulo Freire e principalmente reconhecerem a importância de "ouvir" os alunos, ponto crucial para uma relação dialógica, nos termos freireano.

O desenvolvimento deste projeto de extensão foi permeado todo o tempo por inúmeros desafios, principalmente pela escassa tradição que temos de uma educação fundamentada no diálogo, na perspectiva freireana, todavia, foi um espaço fecundo de aprendizagem para todos os envolvidos.

Um ponto que unia todos os sujeitos desse processo era a ideia de que toda criança deveria ter seus direitos fundamentais garantidos. A educação de qualidade é um deles. Se esse direito está sendo negado, o que pode ser constatado através de inúmeros fatores, contribuir para que essa criança tenha o direito de pronunciar sua palavra no mundo pode ser um caminho para fortalecê-la e viabilizar sua autonomia.

Através do projeto de extensão "Necria e o ECA na escola" foi possivel apreender que o caminho do diálogo não é fácil, é permeado de conflitos, mas é fecundo de possibilidades de aprendizagem. Os desafios, neste processo, foram considerados como conteúdos da aprendizagem. Enfrentar esses desafios inicia-se por compreender que o ato de educar é um ato político que extrapola os muros escolares e a materialização tem como ponto de partida a interpretação do saber do povo (das crianças da escola pública, dos professores, gestores, pais envolvidos e dos estudantes universitários) para identificar formas de lidar com os diferentes saberes que permeiam a relação educador-educando.

Resgatar a essência da extensão universitária tendo como premissa a sua intencionalidade libertária, de contribuição da construção da autonomia dos sujeitos envolvidos, de forma especifica, os extensionistas, também foi uma conquista. A extensão universitária na perspectiva da educação popular reverbera na formação profissional dos estudantes universitários e consequentemente impacta no exercicio da sua profissão. Reconhecer a dimensão dialética teoria-prática através da aproximação com a realidade social contribui com a sua formação critica. Efetivar essa experiência reafirma aos docentes (coordenadores) a necessidade de mobilizar a luta por extensões 
universitárias de caráter educativo, que se somam ao ensino e à pesquisa.

Realizar a educação popular tendo como base a teoria freireana significa realizar um trabalho de conscientização política, ou seja, de leitura crítica do mundo, que caminha junto com o processo de construção e reconstrução do conhecimento e que implica em ação, em intervenção no mundo.

\section{Referências}

Algebaile, E. (2009). Escola pública e pobreza no Brasil: a educação para menos. FAPERJ.

Botomé, S. P. (1996). Pesquisa alienada e ensino alienante: o equivoco da extensão universitária. Vozes.

Freire, P. (1989). A importância do ato de ler: em três artigos que se completam. Cortez.

Freire, P. (2000). Pedagogia da indignação: cartas pedagógicas e outros escritos. Editora UNESP.

Freire, P. (1994). Educação como prática da liberdade. Paz e Terra.

Freire, P. (1982). Pedagogia do Oprimido (11. ed.). Paz e Terra.

Freire, P. (1977). Extensão ou comunicação? Paz e Terra.

Freire, P. (2007). Política e educação (8. ed.). Villa das Letras.

Gramsci, A. (1988). Os intelectuais e a organização da cultura. Civilização.

Kosik, K. (1986). Dialética do concreto. Paz e Terra.

Paulo Netto, J. (1994). Razão, Ontologia e Práxis. Serviço Social \& Sociedade, (44), 26-42.

Paulo Netto, \& Falcão, M. C. (1987). Cotidiano: conhecimento e crítica. Cortez.

Snyders, G. (2005). Escola, Classes e Luta de Classes. Centauro.

\section{Adriana Giaqueto Jacinto}

Pós-doutorado em Serviço Social pela Universidade Estadual do Rio de Janeiro (UERJ), no Rio de Janeiro, Brasil. Docente da Universidade Estadual Paulista Júlio de Mesquita Filho (UNESP), em Franca, SP, Brasil.

\section{Eliana Bolorino Canteiro Martins}

Pós-doutorado em Serviço Social pela Universidade Estadual do Rio de Janeiro (UERJ), no Rio de Janeiro, Brasil. Docente da Universidade Estadual Paulista Júlio de Mesquita Filho (UNESP), em Franca, SP, Brasil.

\section{Endereço para correspondência}

Adriana Giaqueto Jacinto/ Eliana Bolorino Canteiro Martins

Av. Eufrásia Monteiro Petráglia, 900

Jd. Dr. Antonio Petráglia, 14409-160

Franca, SP, Brasil

Os textos deste artigo foram revisados pela Poá Comunicação e submetidos para validação do(s) autor(es) antes da publicação. 